\title{
L5-S1 Disk Prolapse: Pure Endoscopic Approach: Our Experience
}

\author{
Leonello Tacconi* and Paolo Bobicchio \\ Neurosurgical Unit, Azienda Universitaria Integrata, Italy
}

Submission: February 12, 2018; Published: March 14, 2018

*Corresponding author: Leonello Tacconi, FRCS Ed (SN), Azienda Universitaria Integrata, Neurosurgical Unit, Strada di Fiume, 447, Trieste, Italy, Fax: 0039-040-399-4057; Email: leonello.tacconi@asuits.sanita.fvg.it

\begin{abstract}
Background: The endoscopic approach has been introduced in the clinical practice in 1980 with the aim to remove the prolapsed disk and free the compressed nerve using the least disruptive surgical technique and assuring the resolution of the symptoms and a faster return back to normal life activity.
\end{abstract}

Methods: We selected retrospectively 36 patients operated on at the L5-S1 level between January 2016 and June 2017. Twenty-four underwent an interlaminar route and the rest, twelve a transforaminal one. We have analyzed our results in order to assess the best surgical endoscopic technique to reach the L5-S1 disk space.

Results: Immediately after the operation all the patients were fine with an improvement of the pain, we have not had any type of complications and all of them went home 24 hours after the operation. Unfortunately within three months we observed 4 symptomatic disk prolapse recurrence. All four underwent a new operation via an interlaminar approach. At a median follow up of 12 months (range between 7 and 17 months) all 24 cases were fine and back to a normal life.

Conclusion: Our results have confirmed that the endoscopic procedure has become the treatment of choice for lumbar disks erniation also for the L5-S1 level either by a transforaminal or interlaminar approach.

Keywords: Disk prolapsed; Transforaminal; Interlaminar; Endoscopic approach; Recurrent disk prolapse

\section{Introduction}

The endoscopic approach has been introduced in the clinical practice in 1980 with the aim to remove the prolapsed disc and free the compressed nerve using the least disruptive surgical technique and assuring the resolution of the symptoms and a faster return back to normal life activity [1,2]. Over the years we have assisted to an extraordinary technical improving either in terms of quality of images and development of many different endoscopic instruments. Furthermore, many publications have proven the efficacy of this surgical technique in achieving an adequate nerve root decompression with a small percentage of symptoms recurrence or complications. As matter of fact the endoscopic removal of a lumbar disc prolapse is becoming the standard technique in the treatment of lumbar discs protrusion [1]. Endoscopic technique may have, however, some disadvantages like a longer learning curve when compared with the microsurgical technique and the problem to reach easily the L5-S1 space by a transforaminal route because of a high iliac crest. This specific disk space can be however reached also by an interlaminar endoscopic approach [3]. This double technical possibility raises the questions which one may be the best route or it would be better to say when to use one or the other [4]. In order to share our experience regarding this matter we have identified a group of such patients.

\section{Materials and Methods}

We selected retrospectively 36 patients operated on at the L5-S1 level between January 2016 and June 2017. We decided to exclude cases performed at the beginning of our learning curve. Twenty-four underwent an interlaminar route and the rest, twelve a transforaminal one (Table 1). The operations were all performed by the first author. The mean age was 39 years old (range between 23 and 67) with a male preponderance of 55\%. The duration of symptoms varied from 7 weeks to 4 months. The main complain was leg pain in all cases and in three (12.5\%) was also present a difficulty in tip-toes walking.

Table 1: Interlaminar/transforaminal distribution.

\begin{tabular}{|c|c|c|}
\hline Approaches & Interlaminar & Transforaminal \\
\hline & 24 & 12 \\
\hline
\end{tabular}




\section{Open Access Journal of Neurology \& Neurosurgery}

\section{Results}

Immediately after the operation all the patients were fine with an improvement of the pain, we have not had any type of complications and all of them went home 24 hours after the operation. Unfortunately within three months we observed 3 symptomatic disk prolapse recurrence (8.3\%) (Table 2). All three underwent a new operation via an inter laminar approach. Two always with an endoscopic technique; the other one, where the disk was centrally located and with some calcifications, we elected to perform a microsurgical standard approach. In all three cases the pain improved. At a median follow up of 12 months (range between 7 and 17 months) all 36 cases were fine and back to a normal life.

Table 2: Recurrent disk prolapsed with regard to the type of surgical approach used.

\begin{tabular}{|c|c|c|c|}
\hline Approaches & $\begin{array}{c}\text { Number of } \\
\text { Patients }\end{array}$ & Recurrence & Complications \\
\hline Transforaminal & 12 & $3(25 \%)$ & $/$ \\
\hline Interlaminar & 24 & $/$ & $/$ \\
\hline
\end{tabular}

\section{Discussion}

The surgical technique we have used was the transforaminal one in all cases with favorable anatomy (low iliac crest or a downwards pointing disk prolapse) or the interlaminar one. In all cases the patients were in the prone position, under general anesthesia (GA) without muscles relaxant. For the transforaminal route a lateral entry point (about $12-14 \mathrm{~cm}$ from the midline) by A-P and Lateral $\mathrm{x}$-ray is identified and the lower part of the foramen is reached passing through the safe zone (Kambin's Triangle [5]) and the foramen entered (Figure 1). At this point progressive tubes are inserted to dilate the muscle. If necessary same different size trimmers can be used to enlarge the foramen. The disc removal and the nerve root identification are done under direct vision. Also for the interlaminar approach the patient was under GA and placed in the prone position. With this technique a more midline approach is used, generally a couple of $\mathrm{cm}$ from the midline. However under AP x-ray controls the entry point is chosen (Figure 2), an eight mm skin incision length is performed and the muscles are dilated down until the lamina. In this approach the vision is very similar to the one we have under the microscope: the dura, the origin of the affected nerve root and the protruded disc are first identified and then the disk removed. The length of these two procedures is very similar being around 65 minutes. The interlaminar approach can, however, be performed in all cases with disregard to the height of the iliac crest. It is our opinion, however that the transforaminal one is less invasive in terms of anatomy disruption [6]. The types of approaches chosen with regard to the location of the disk are summarized in Table 3. We have also tried to analyze the three cases of recurrent disk with regard to the chosen approach and the disk location. The number are too small to make any firm conclusion but all three recurrences (25\%) were in the group of transforaminal approach with the disk migrated upwards.
This consideration opens up the question about the best surgical approach with respect to the disk location. If the disk is migrated upwards there is no possibility that the disc can be removed easily by a transforaminal route. If, instead, the disk is at his normal disk-space level or it is migrated downwards, this can be the perfect indication for using a transforaminal route despite the height of the iliac crest because we would need a more acute angle trajectory.

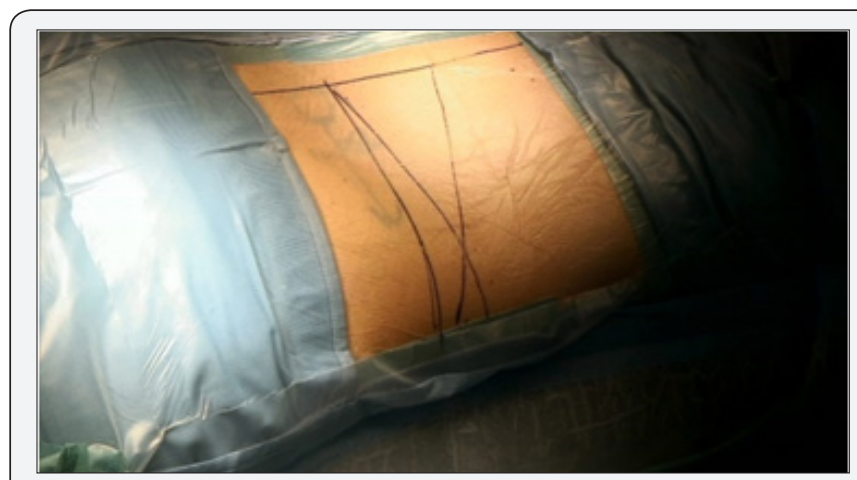

Figure 1: Entry point in the transforaminal approach.

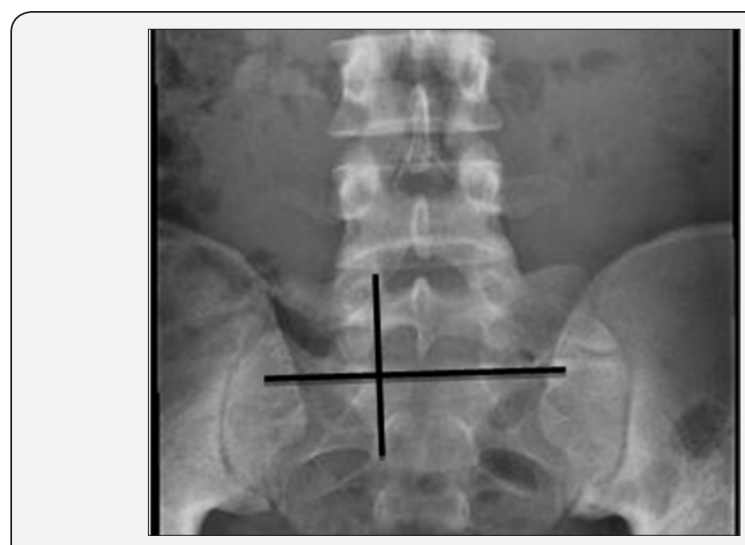

Figure 2 : Entry point in the interlaminar approach.

Table 3: Distribution and surgical types of approach in relation to the disk's location.

\begin{tabular}{|c|c|c|c|}
\hline Approaches & $\begin{array}{c}\text { Foraminal } \\
\text { Located } \\
\text { and Upward } \\
\text { Migrated }\end{array}$ & $\begin{array}{c}\text { Paracentral } \\
\text { and Centrally } \\
\text { Located }\end{array}$ & $\begin{array}{c}\text { Downwards } \\
\text { Migrated }\end{array}$ \\
\hline $\begin{array}{c}12 \\
\text { Transforaminal }\end{array}$ & 4 & 3 & 5 \\
\hline $\begin{array}{c}24 \\
\text { Interlaminar }\end{array}$ & 9 & 12 & 3 \\
\hline
\end{tabular}

If we consider the outcome looking at the Visual Analogue Scale (VAS) or at the Oswestry Disability Index (ODI) results we believe it is good. As matter of fact the VAS started from a median value of 5.6 and went down to a median VAS of 1.5 at twelve months (Graph 1). Regarding the ODI results we went from a starting value of $51 \%$ to a value of $10 \%$ at twelve months (Graph 2). 


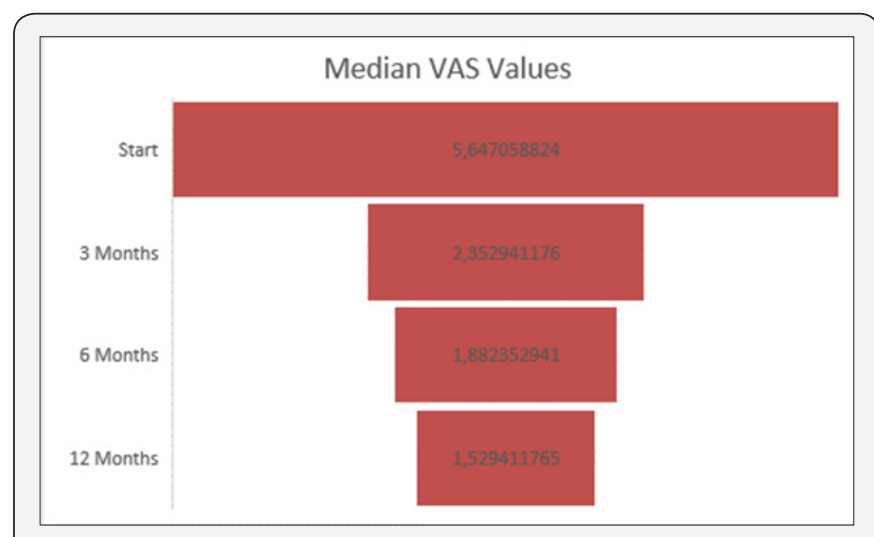

Graph 1 : Median VAS Values.

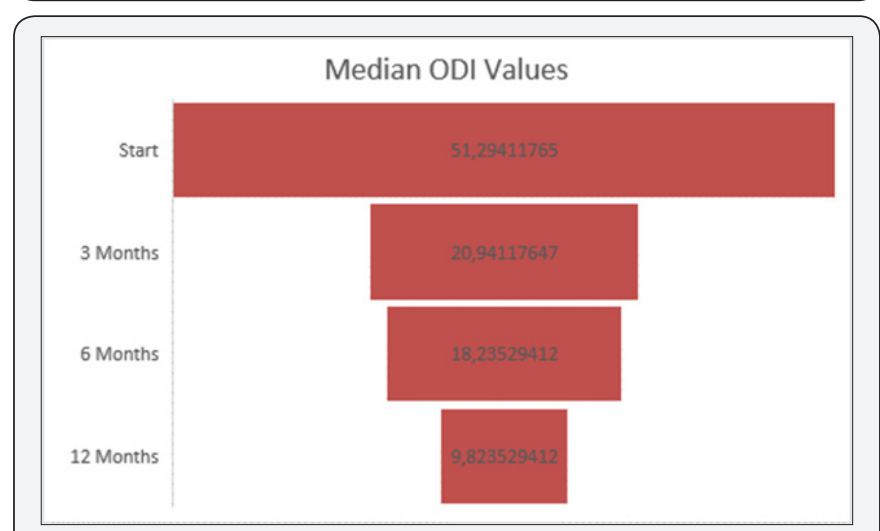

Graph 2 : Median ODI Values.

\section{Conclusion}

The results we have had from our series, although small, have confirmed that the endoscopic procedure has become the treatment of choice for lumbar disks erniation also for the L5-S1 level either by a transforaminal or interlaminar approach if we are looking for a very minimal invasive surgical technique (VMIST). As other author have pointed out [2] the interlaminar approach is the one which is more similar to the open microsurgical technique and therefore it needs a shorter learning curve. This approach is also more flexible in being able to reach a migrated disk. However the best clinical results can be achieved only if the approache choice keeps in mind the location of the prolapsed disk $[7,8]$.

\section{References}

1. Lee JS, Kim HS, Jang JS, Jang IT (2016) Structural preservation percutaneous endoscopic lumbar interlaminar discectomy for L5-S1 herniated nucleus pulposus. Biomed Res Int 2016: 6250247.

2. Yang JS, Zeng YS, Liu TJ, Hao DJ (2017) Full-endoscopic procedures versus traditional discectomy surgery for discectomy: a systematic review and meta-analysis of current global clinical trials. Pain Physician. 20(7): E1123-E1124.

3. Kim HS, Park JY (2013) Comparative assessment of different percutaneous endoscopic interlaminar lumbar discectomy (PEID) techniques. Pain Physician. 16(4): 359-367

4. Choi KC, Kim JS, Park CK (2016) Percutaneous endoscopic lumbar discectomy as an alternative to open lumbar microdiscectomy for large lumbar disc herniation. Pain Physician 19(2): E291-E300.

5. Park JW, Nam HS, Cho SK, Jung HJ, Lee BJ, et al. (2011) Kambin's triangle approach of lumbar transforaminal epidural injection with spinal stenosis . Ann Rehabil Med 35(6): 833-843.

6. Kim HS, Yudoyono F, Paudel B, Kim KJ, Jang JS, et al. (2017) Analysis of clinical results of three different routes of percutaneous endoscopic transforaminal lumbar discectomy for lumbar herniated. Disk. World Neurosurg. 103: 442-448.

7. Choi KC, Kim JS, Ryu KS, Kang BU, Ahn Y, et al. (2013) Percutaneous endoscopic lumbar discectomy for L5-S1 disc herniation: transforaminal versus interlaminar approach. Pain Physician 16(6): 547-556.

8. Pan Z, Ha Y, Yi S, Cao K (2016) Efficacy of transforaminal endoscopic spine system (tessys) technique in treating lumbar disc herniation. Med Sci Monit 22: 530-539.

\begin{tabular}{l} 
Your next submission with Juniper Publishers \\
will reach you the below assets \\
- Quality Editorial service \\
- Swift Peer Review \\
- Reprints availability \\
- E-prints Service \\
- Manuscript Podcast for convenient understanding \\
- Global attainment for your research \\
- Manuscript accessibility in different formats \\
( Pdf, E-pub, Full Text, Audio) \\
- Unceasing customer service \\
Track the below URL for one-step submission \\
https://juniperpublishers.com/online-submission.php \\
\hline
\end{tabular}

